Article

\title{
Aflatoxins, Fumonisins and Zearalenone Contamination of Maize in the Southeastern and Central Highlands Provinces of Vietnam
}

\section{Nguyen Hieu Phuong ${ }^{1, *}$, Nguyen Quang Thieu ${ }^{1}$, Brian Ogle ${ }^{2}$ and Hans Pettersson ${ }^{2}$}

1 Faculty of Animal Science and Veterinary Medicine, Nong Lam University, Linh Trung Ward, Thu Duc District, Ho Chi Minh City, Vietnam; E-Mail: nguyen.quangthieu@hcmuaf.edu.vn

2 Department of Animal Nutrition and Management, Swedish University of Agricultural Sciences, P.O. Box 7024, SE-750-07 Uppsala, Sweden; E-Mails: brian.ogle@btinternet.com (B.O.); hans.pettersson@slu.se (H.P.)

* Author to whom correspondence should be addressed; E-Mail: phuongnguyen180984@yahoo.com.

Academic Editor: Wayne L. Bryden

Received: 30 August 2015 / Accepted: 26 November 2015 / Published: 4 December 2015

\begin{abstract}
A survey of the contamination of maize with aflatoxins, fumonisins and zearalenone was carried out in the Southeastern and Central Highland provinces in Vietnam. Four provinces were chosen for sampling maize: Dong Nai (22), Binh Phuoc (25), Dak Lak (30) and Dak Nong (20). Aflatoxin $\mathrm{B}_{1}\left(\mathrm{AFB}_{1}\right), \mathrm{B}_{2}\left(\mathrm{AFB}_{2}\right), \mathrm{G}_{1}\left(\mathrm{AFG}_{1}\right), \mathrm{G}_{2}\left(\mathrm{AFG}_{2}\right)$, fumonisin $\mathrm{B}_{1}\left(\mathrm{FB}_{1}\right)$, fumonisin $\mathrm{B}_{2}\left(\mathrm{FB}_{2}\right)$ and zearalenone (ZEA) were analysed by HPLC in 97 maize kernel samples. Fumonisins were the most common toxins found in all samples (67\%), followed by aflatoxins $(55.7 \%)$ and zearalenone $(27.8 \%)$. The incidence of aflatoxin positive samples $(61.7 \%)$ in the Southeastern provinces was higher than in the Central Highlands (50\%), while fumonisins and zearalenone incidences were higher in the Central Highlands. The mean level of fumonisin $\mathrm{B}_{1}$ in samples from the Central Highlands provinces $(1757 \mu \mathrm{g} / \mathrm{kg})$ was significantly greater $(p<0.05)$ than in the Southeastern provinces $(740 \mu \mathrm{g} / \mathrm{kg}$ ). Importantly, the percentage of positive samples (about $70 \%$ ) that had over $20 \mu \mathrm{g} / \mathrm{kg}$ (ppb) aflatoxin was very high. Moreover, many samples (53\%) contained more than one mycotoxin and this result highlights the difficulty of diagnosing mycotoxicoses in the field and the need for ongoing research to reduce the occurrence of mycotoxins in Vietnamese maize.
\end{abstract}


Keywords: aflatoxins; fumonisins; zearalenone; maize; Vietnam

\section{Introduction}

The significance of the effects of mycotoxins on animal production and human health has been known since the 1960s [1]. Mycotoxins are fungal metabolites which have low molecular weights that are not recognized by the body's immune system and are insidious poisons [2]. Moreover, many mycotoxin-producing fungi are also plant pathogens, leading to economic crop losses. These toxins can be formed in many stages of plant production, from growing to harvest, drying, and storage [2,3]. Among the many different mycotoxins, aflatoxins, fumonisins and zearalenone are well known owing to their occurrence and toxicities, especially in animals [4]. Aflatoxins are produced by Aspergillus spp. including A.flavus, A. parasiticus, A. nomius, and A. pseudotamarii, and there are four major aflatoxins: $\mathrm{B}_{1}, \mathrm{~B}_{2}, \mathrm{G}_{1}$ and $\mathrm{G}_{2}$ [3,5]. Maize and peanuts are important crops that are often contaminated with aflatoxins [6]. The aflatoxins are considered the most important mycotoxin because of its toxicity and designation as a carcinogen [1-3]. The disease resulting from aflatoxin ingestion is aflatoxicosis and in livestock it may result in reduced growth performance, changes in some liver enzymes, liver damage, decreased milk and egg production and reduced immune response [2-4]. Fumonisins are mycotoxins, produced predominantly by Fusarium verticillioides (previously $F$. moniliforme) and $F$. proliferatum with four main types, $\mathrm{B}_{1}, \mathrm{~B}_{2}, \mathrm{~A}_{1}, \mathrm{~A}_{2}$, of which fumonisin $\mathrm{B}_{1}$ is produced in the largest amount and has the highest toxicity [7]. The fumonisins cause equine leukoencephalomalacia, and pulmonary edema in pigs and may induce esophageal cancer and neural tube defects in humans [7-9]. Fumonisin $\mathrm{B}_{1}$ is commonly found in maize and maize-based food and feed in Africa, China, France, Indonesia, Italy, the Philippines, South America, Thailand, and the USA [7,10,11]. In Southeast Asia, fumonisins are the most prevalent mycotoxin detected, with $58 \%$ positive samples, and maize is the most contaminated feed, with $71 \%$ positive samples [12]. Zearalenone is also produced by many species of the Fusarium genus and is a mycotoxin with estrogenic characteristics [13]. In this genus, Fusarium graminearum is the most widely distributed species that produces zearalenone in wheat and maize world-wide [14]. Zearalenone toxicity mostly affects the reproductive function of animals, especially pigs, by inducing feminization, decreasing the number of fetuses per sow and reducing sow fertility $[13,15]$.

Of the cereal grains, maize is the crop most affected by mycotoxin contamination [16]. In Vietnam, maize is the second most important human food staple after rice, particularly in the rural and mountainous areas. It is also the main energy feed source for Vietnam's livestock industries. The Southeast region-Mekong Delta Upland is an agro-ecological zone with the second largest maize growing area in Vietnam, followed by the Central Highlands-Central Coast Upland [17]. The Southeastern and Central Highlands provinces are in the tropical monsoon region where weather conditions are favorable for the production of many mycotoxins. However, the mycotoxin contamination of maize grown in these regions has not been examined in detail. Therefore, a survey on the occurrence of fumonisins, aflatoxins and zearalenone in maize obtained from four provinces in the Southeastern Mekong Delta Uplands and Central Highlands of Vietnam was conducted. 


\section{Results and Discussion}

The occurrence of mycotoxins in the two study areas is shown in Table 1, and was different among the toxins. The Southeastern provinces had about a 10\% higher incidence of aflatoxin contaminated samples than in the Central Highlands. In contrast, the incidence of zearalenone and fumonisins positive samples was higher in the Highlands provinces than in the Southeast. Overall, the highest percentage of samples was contaminated with fumonisins (67\%), followed by aflatoxins (55.7\%) and zearalenone (27.8\%). Two worldwide surveys of the occurrence of mycotoxins have been published for the periods 2003-2005 [12] and 2009-2011 [18]. Both surveys included data from Southeast Asia (Malaysia, Philippines, Thailand, Indonesia and Vietnam). The results in the present study are in accordance with the occurrence of the toxins found in Southeast Asia, where fumonisins were also the most commonly found mycotoxin, followed by aflatoxins. A similar result was found in a preliminary survey of maize samples from Vietnam [19]. In contrast, Trung et al. [20] conducted a survey by collecting samples from North, Central and South Vietnam that showed $68 \%$ of tested samples were contaminated with $\mathrm{AFB}_{1}$, while the percentage of fumonisin $\mathrm{B}_{1}$ positive samples was only $32 \%$.

Table 1. Occurrence of aflatoxins, fumonisins and zearalenone in samples of maize from the Southeastern Mekong Delta Uplands and Central Highlands of Vietnam.

\begin{tabular}{|c|c|c|c|c|c|c|c|c|c|}
\hline \multirow{2}{*}{ Samples } & \multicolumn{3}{|c|}{ Aflatoxins } & \multicolumn{3}{|c|}{ Fumonisins } & \multicolumn{3}{|c|}{ Zearalenone } \\
\hline & $\mathbf{D N}+\mathbf{B P}^{\mathrm{a}}$ & $\mathbf{D N}+\mathbf{D L}^{\mathrm{a}}$ & Total & $\mathbf{D N}+\mathbf{B P} \mathbf{a}^{\mathbf{a}}$ & $\mathbf{D N}+\mathbf{D L}^{\mathbf{a}}$ & Total & $\mathbf{D N}+\mathbf{B P}^{\mathrm{a}}$ & $\mathbf{D N}+\mathbf{D L}^{\mathrm{a}}$ & Total \\
\hline Analyzed ( $n$ ) & 47 & 50 & 97 & 47 & 50 & 97 & 47 & 50 & 97 \\
\hline Positive (n) & 29 & 25 & 54 & 26 & 39 & 65 & 5 & 22 & 27 \\
\hline Positive (\%) & 61.7 & 50.0 & 55.7 & 55.3 & 78.0 & 67.0 & 10.6 & 44.0 & 27.8 \\
\hline
\end{tabular}

${ }^{\mathrm{a}}$ DN + BP: Dong Nai + Binh Phuoc; DN + DL: Dak Nong + Dak Lak provinces.

The distribution of aflatoxins, fumonisins and zearalenone were different between the Southeast Mekong Delta uplands and Central Highlands (Table 2). The aflatoxins tend to be more common in Dong Nai and Binh Phuoc provinces. These provinces have higher mean temperatures than Dak Nong and Dak Lak, which provides good conditions for the production of aflatoxins [2]. Moreover, most of the samples collected in Binh Phuoc were not dried well and were stored in poor conditions in the houses of small farmers. Both factors may have contributed to the high percentage of AF positive samples in both the Southeastern provinces and the Central Highlands. Fumonisins and zearalenone on the other hand were more common in samples from the Central Highlands. The fusarium toxins develop more rapidly in fields under condition of high air humidity and moderate temperatures, which are more prevalent in Central Highlands than in the Southeastern provinces [14].

The results in Table 2 show very clearly that the mean $\mathrm{FB}_{1}$ level in DN + DL was significantly higher than in $\mathrm{DN}+\mathrm{BP}(p<0.05)$. Moreover, the median and concentration range of $\mathrm{FB}_{1}$ in $\mathrm{DN}+\mathrm{DL}$ were also much higher and wider than in $\mathrm{DN}+\mathrm{BP}$. Although aflatoxin $\mathrm{B}_{1}$ concentration in $\mathrm{DN}+\mathrm{DL}$ samples was not significantly higher than in $\mathrm{DN}+\mathrm{BP}$, the aflatoxin $\mathrm{B}_{2}$ mean value in $\mathrm{DN}+\mathrm{DL}$ tended to be higher than in DN + BP $(p=0.071)$, and one sample from Dak Lak had $810 \mathrm{ppb}$ of AFG 1 . The mean concentrations of aflatoxin $\mathrm{B}_{1}$ in these two areas were much higher than the maximum tolerated level mandated by the European Union (EU, $5 \mu \mathrm{g} / \mathrm{kg}$ ) and U.S. Food and Drug Administration Compliance Policy Guides for maize (FDA, $20 \mu \mathrm{g} / \mathrm{kg}$ ). Furthermore, the concentrations of toxins in DN + DL had 
wider ranges than in $\mathrm{DN}+\mathrm{BP}$. These ranges were also wider than the fumonisin $\mathrm{B}_{1}$ range in samples from North, Central and South Vietnam (400-3300 ppb), and aflatoxin B1 range (7-126.5 ppb) reported in the survey conducted by Trung et al. [20]. Although there was no significant difference between zearalenone contents in samples from the Southeast Upland and Central Highlands, the mean and range of this toxin in DN + DL was higher than in DN + BP.

Table 2. Aflatoxins, fumonisins and zearalenone levels $(\mu \mathrm{g} / \mathrm{kg})$ in maize from the Southeast Mekong Delta Uplands and Central Highlands of Vietnam.

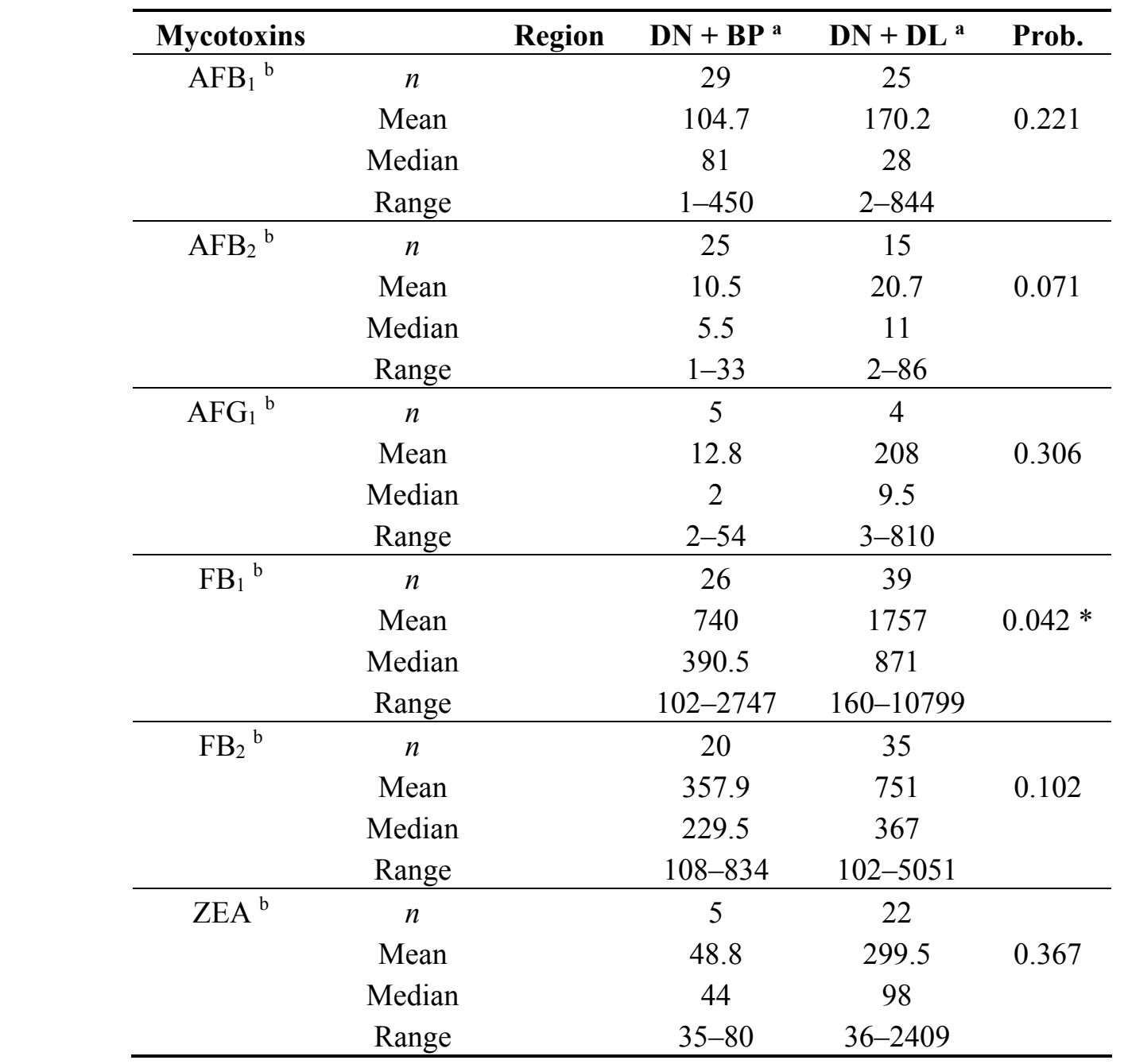

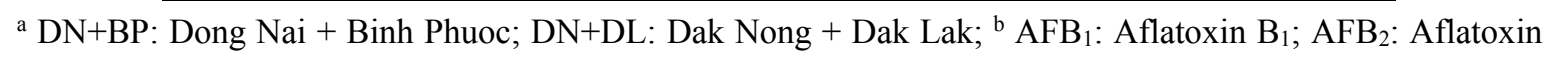
$\mathrm{B}_{2} ; \mathrm{AFG}_{1}$ : Aflatoxin $\mathrm{G}_{1} ; \mathrm{FB}_{1}$ : Fumonisin $\mathrm{B}_{1} ; \mathrm{FB}_{2}$ : Fumonisin $\mathrm{B}_{2}$; ZEA: Zearalenone; ${ }^{*} p<0.05$.

The number of toxins in a contaminated sample is shown in Figure 1. Only 16\% of samples had no detectable toxins, whilst $31 \%$ contained one mycotoxin and the remaining $53 \%$ were contaminated with more than one toxin. This result is similar to the results for Southeast Asia which appeared in the two world surveys $[12,18]$.

The distribution of aflatoxin concentrations in the samples is shown in Table 3. The percentage of positive samples that had over $20 \mathrm{ppb}$ aflatoxin was very high (about 70\%). Moreover, the occurrence of samples with over $300 \mu \mathrm{g} / \mathrm{kg}$ (ppb) was higher than the occurrence of samples with from 98.4 to $126.5 \mathrm{ppb}$ in the survey of Trung et al. [20] $(14.8 \%>11.8 \%)$. 


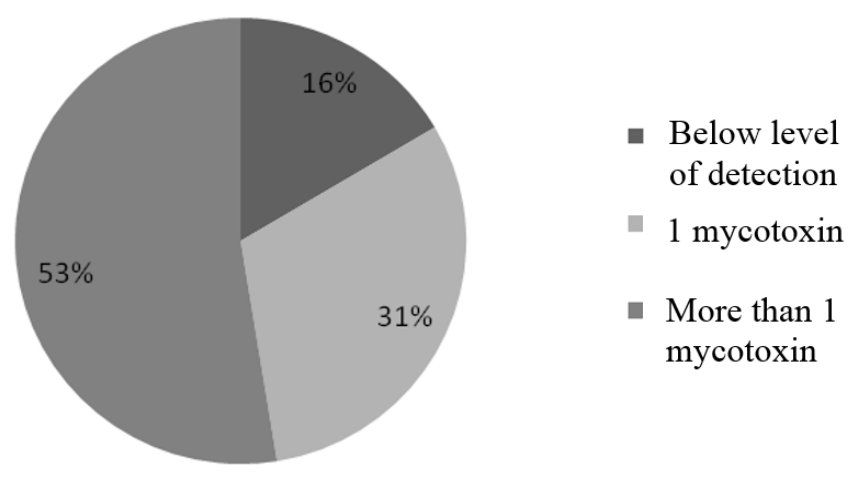

Figure 1. The co-occurrence of mycotoxins in maize kernels sampled in Vietnam.

Table 3. Distribution of total aflatoxin levels in maize kernel samples.

\begin{tabular}{ccc}
\hline Aflatoxins $(\boldsymbol{\mu g} / \mathbf{k g})$ & Frequency & \% of Samples \\
\hline $0 \leq 20$ & 17 & 31.5 \\
$21-100$ & 14 & 25.9 \\
$101-300$ & 15 & 27.8 \\
$>300$ & 8 & 14.8 \\
\hline
\end{tabular}

The distribution of fumonisin concentrations in the samples is shown in Table 4. The majority (90\%) of samples analysed had fumonisin concentrations of less than $4000 \mathrm{ppb}$ (4 ppm). The occurrence of positive samples with over 12,000 ppb was low (3.1\%).

Table 4. Distribution of total fumonisins levels in maize kernel samples.

\begin{tabular}{ccc}
\hline Fumonisins $(\boldsymbol{\mu g} / \mathbf{k g})$ & Frequency & \% of Samples \\
\hline $0 \leq 4000$ & 59 & 90.8 \\
$4001-8000$ & 3 & 4.6 \\
$8001-12,000$ & 1 & 1.5 \\
$>12,000$ & 2 & 3.1 \\
\hline
\end{tabular}

The distribution of zearalenone concentrations in the samples is shown in Table 5. Zearalenone positive samples that contained less than $100 \mathrm{ppb}(0.1 \mathrm{ppm})$ was high $(63 \%)$ and about $11 \%$ of samples contained over $500 \mathrm{ppb}$. In comparison, a Brazillian survey showed only about $17 \%$ positive samples with less than $100 \mathrm{ppb}$, and $6.7 \%$ samples with over $500 \mathrm{ppb}$ [21].

Table 5. Distribution of zearalenone levels in maize kernel samples.

\begin{tabular}{ccc}
\hline Zearalenone $(\boldsymbol{\mu g} / \mathbf{k g})$ & Frequency & \% of Samples \\
\hline $0 \leq 100$ & 17 & 63.0 \\
$<100-500$ & 7 & 25.9 \\
$500-1000$ & 1 & 3.7 \\
$>1000$ & 2 & 7.4 \\
\hline
\end{tabular}




\section{Experimental Section}

\subsection{Site Description}

Two provinces in the Southeastern Mekong Delta Uplands, Binh Phuoc and Dong Nai, and two in the Central Highlands, Dak Lak and Dak Nong, were chosen for the survey, since their maize production is well developed and is used for livestock in the area.

\subsubsection{Dong Nai and Binh Phuoc-Warm Region}

These provinces are located in the tropical monsoon area; the climate is hot and humid, with two seasons, a rainy season from May to November and a dry season from December to April. The average rainfall is from 1800 to $2000 \mathrm{~mm}$ per year, relative humidity is $80 \%$ to $90 \%$, and average temperature is about $27{ }^{\circ} \mathrm{C}$. This area has an elevation ranging from 100 to $200 \mathrm{~m}$ above sea level. This region has the second largest planted maize area in Vietnam with two rain-fed maize crops per year; the summer-autumn and autumn-winter. Maize grown in these provinces is mainly for commercial production, owing to the good transportation system and the proximity to feed mills. In these provinces, the maize area is usually around $1.0 \mathrm{ha}$, and it is an important source of income for the farmers [17].

\subsubsection{Dak Lak and Dak Nong - Cool Region}

These provinces are located in the Central Highlands region, at 500 to $800 \mathrm{~m}$ above sea level, in the tropical monsoon area, with two seasons, a rainy season from May to November and a dry season (from December to April). The average temperature is from 18 to $25{ }^{\circ} \mathrm{C}$, so it is relatively cool throughout the year. The average rainfall is from $1750 \mathrm{~mm}$ to $3150 \mathrm{~mm}$ per year and relative humidity is around $85 \%$ to $87 \%$. There is one rain-fed maize crop per year, grown in the summer-autumn season. Maize is mainly grown in semi-commercial production systems on sloping land. The infrastructure in many places is poor and although the farmers own on average 1.3 ha for maize cultivation, there are still many poor families in the rural areas [17].

\subsection{Sampling Method}

A total of 97 maize kernel samples (about $1 \mathrm{~kg}$ per sample) was purchased from local retail traders and small farmers in the four provinces of Southeastern and Central highlands of Vietnam from the end of August to the beginning of October 2009, the maize harvesting season. The number of samples was 22, 25, 20 and 30 from Dong Nai, Binh Phuoc, Dak Nong and Dak Lak, respectively. Samples were dried in an oven at $60{ }^{\circ} \mathrm{C}$ for $8 \mathrm{~h}$ then stored in plastic bags with a desiccator (silica gel in small bags to stop mould activity) at room temperature before analysis.

\subsection{Mycotoxin Analysis Methods}

The methods used for aflatoxins, fumonisins and zearalenone analyses, including sample preparation, clean-up and HPLC analysis have been detailed by Binder et al. [12]. The procedures were completed by Romer Labs, Singapore. 
Briefly, aflatoxins and zearalenone were extracted from $25 \mathrm{~g}$ milled samples using $100 \mathrm{~mL}$ acetonitrile/water (84:16) and $4 \mathrm{~mL}$ filtrate was cleaned-up on a Mycosep \#226 AflaZon cartridge. The fumonisins were extracted separately from another $25 \mathrm{~g}$ sample using $100 \mathrm{~mL}$ acetonitrile/water (50:50). Filtrate was adjusted to $\mathrm{pH} 6-9$ and $3 \mathrm{~mL}$ was diluted in $8 \mathrm{~mL}$ methanol/water (3:1) and passed through a Multisep 211 column, washed with $8 \mathrm{~mL}$ methanol/water (3:1) and eluted with $10 \mathrm{~mL}$ methanol/acetic (99:1).

The aflatoxins were analyzed using HPLC with separation on a Zorbax SB-Aq column $(4.6 \times 150 \mathrm{~mm}$, $5 \mu \mathrm{m})$ at $30{ }^{\circ} \mathrm{C}$ with mobile phase water/acetonitrile/methanol $(5: 1: 1)$, flow rate $2 \mathrm{~mL} / \mathrm{min}$ and post-column derivatization using a Kobra cell and fluorescence detection (excitation wavelenght at $360 \mathrm{~nm}$ and emission wavelenght at $440 \mathrm{~nm}$ ).

Zearalenone was also analyzed by HPLC on a Hypersil ODS column $(2.1 \times 100 \mathrm{~mm}, 5 \mu \mathrm{m})$ using an isocratic mobile phase water/acetonitrile (64:36), column temperature $30^{\circ} \mathrm{C}$ and fluorescence detection (excitation wavelenght at 235 and emission wave length at $460 \mathrm{~nm}$ ).

Fumonisins were precolumn derivatized with naphthalene 2,3-dicarboxaldehyde before HPLC separation on a Hypersil ODS (Octadecylsilan) column $(2.1 \times 200 \mathrm{~mm}, 5 \mu \mathrm{m})$ using mobile phase acetonitrile/water/methanol/acetic acid $(48 / 46 / 5 / 1)$ at a flow rate of $0.5 \mathrm{~mL} / \mathrm{min}$ and fluorescence detection (excitation wavelength at $420 \mathrm{~nm}$ and emission wavelenght at $500 \mathrm{~nm}$ ).

Normal recovery from spiked samples was $80 \%$ for $\mathrm{AFB}_{1}, 100 \%$ for zearalenone and $75 \%$ for fumonisins. The limit of quantification was $1 \mu \mathrm{g} / \mathrm{kg}$ for $\mathrm{AFB}_{1}, 25-32 \mu \mathrm{g} / \mathrm{kg}$ for zearalenone and $100 \mu \mathrm{g} / \mathrm{kg}$ for fumonisins. Control samples were used for quality control of the routine analyses.

\subsection{Data Analysis}

The data were calculated and analysed using the Excel program, with the incidence of positive aflatoxin, fumonisin and zearalenone samples in the total, range, mean and median values. The distribution of aflatoxin, fumonisin and zearalenone levels in maize kernels was also calculated by Excel. The differences in aflatoxin, fumonisin and zearalenone concentration in maize between the Southeastern provinces and Central Highlands were compared by ANOVA in Minitab 13 (Minitab Inc., Pennsylvania, PA, USA). Sources of variance were geographical areas and error.

\section{Conclusions}

Maize kernel samples from the Southeastern and Central Highlands of Vietnam were frequently contaminated with aflatoxins and fumonisins at high concentrations. Aflatoxin $\mathrm{B}_{1}$ levels were much higher than the maximum tolerated $\mathrm{AFB}_{1}$ level of both the European Union and the Food and Drug Aministration. Therefore, maize from these regions can be considered as a major health problem for the consumers. In the Central Highlands, the incidence of positive maize samples contaminated with fumonisins and zearalenone was higher than in the Southeastern provinces. Although fumonisins or zearalenone contamination incidences were higher than aflatoxins, their levels of contamination were mostly within acceptable range. On the other hand, aflatoxins seem to be a major problem due to their high levels of contamination. Many samples contained more than one mycotoxin and this result highlights the difficulty of diagnosing mycotoxicoses in the field due to the synergistic effects of 
mycotoxins on animals. These results emphasize the need for ongoing research to reduce the occurrence of mycotoxins in Vietnamese maize.

\section{Acknowledgments}

We would like to thank Preston for his valuable advice and helpful corrections and Romer Labs, Singapore for analyses. This work was financially supported by the Swedish International Development Cooperation Agency (SIDA) and Biomin Holding GmbH.

\section{Author Contributions}

P.N.H. and T.N.Q. conceived and designed the survey; P.N.H. performed the survey; P.N.H. and T.N.Q. analyzed the data; B.O. and H.P. gave advice and contributed to the preparation of the paper.

\section{Conflicts of Interest}

The authors declare no conflicts of interest.

\section{References}

1. Richard, J.L. Some major mycotoxins and their mycotoxicoses-An overview. Int. J. Food Microbiol. 2007, 119, 3-10.

2. Bryden, W.L. Mycotoxins and mycotoxicoses: Significance, occurrence and mitigation in the food chain. In General and, Applied Toxicology, 3rd ed.; John Wiley \& Sons, Ltd.: Chichester, UK, 2009; pp. 3529-3553.

3. CAST. Mycotoxins: Risks in Plant, Animal, and Human Systems; Council for Agricultural Science and Technology: Ames, IA, USA, 2003.

4. Pettersson, H. Controlling mycotoxins in animal feed. In Mycotoxins in Food; Magan, N., Olsen, M., Eds.; Woodhead Publishing: Cambridge, UK, 2004; pp. 262-304.

5. Abbas, H.K., Ed.; In Aflatoxin and Food Safety; CRC Press: Boca Raton, FL, USA, 2005; pp. 13-28.

6. Reddy, K.R.N.; Abbas, H.K.; Abel, C.A.; Shier, W.T.; Oliveira, C.A.F.; Raghavender, C.R. Mycotoxin contamination of commercially important agricultural commodities. Toxin Rev. 2009, $28,154-168$.

7. Voss, K.A.; Smith, G.W.; Haschek, W.M. Fumonisins: Toxicokinetics, mechanism of action and toxicity. Anim. Feed Sci. Tech. 2007, 137, 299-325.

8. Gelineau-van Waes, J.; Starr, L.; Maddox, J.; Aleman, F.; Voss, K.A.; Wilberding, J.; Riley, R.T. Maternal fumonisin exposure and risk for neural tube defects: Mechanisms in an in vivo mouse model. Birth Defects Res. A Clin. Mol. Teratol. 2005, 73, 487-497.

9. Marasas, W.O. Fumonisins: History, world-wide occurrence and impact. In Fumonisins in Food; Jackson, L., DeVries, J., Bullerman, L., Eds.; Springer US: New York, NY, USA, 1996; Volume 392, pp. 1-17.

10. CTA. Mycotoxins in Grain; CTA: Wageningen, The Netherlands, 1997.

11. Soriano, J.M.; Dragacci, S. Occurrence of fumonisins in food. Food Res. Int. 2004, 37, 985-1000. 
12. Binder, E.M.; Tan, L.M.; Chin, L.J.; Handl, J.; Richard, J. Worldwide occurrence of mycotoxins in commodities, feeds and feed ingredients. Anim. Feed Sci. Tech. 2007, 137, 265-282.

13. Summerell, B.A.; Leslie, J.F.; Backhouse, D.; Bryden, W.L.; Burgess, L.W., Eds.; Fursarium: Paul E. Nelson Memorial Symposium; APS Press: St Paul, MN, USA.

14. Desjardins, A.E. Fusarium Mycotoxins: Chemistry Genetics and Biology; APS Press: St Paul, MN, USA, 2005.

15. Fink-Gremmels, J.; Malekinejad, H. Clinical effects and biochemical mechanisms associated with exposure to the mycoestrogen zearalenone. Anim. Feed Sci. Tech. 2007, 137, 326-341.

16. Miller, J.D. Mycotoxins in small grains and maize: Old problems, new challenges. Food Add. Contam. A 2008, 25, 219-230.

17. Dinh Thao, T.; Tri Khiem, N.; Xuan Trieu, M.; Gerpacio, R.V.; Pingali, P.L. Maize in Vietnam: Production Systems, Constraints, and Research Priorities; CIMMYT: Mexico, D.F., Mexico, 2004.

18. Rodrigues, I.; Naehrer, K. A three-year survey on the worldwide occurrence of mycotoxins in feedstuffs and feed. Toxins 2012, 4, 663-675.

19. Miraglia, M.; van Egmond, H.; Brera, C.; Gilbert, J. Mycotoxins and Phytotoxins. In $I X$ International Iupac Symposium on Mycotoxins and Phycotoxins; Alaken, Inc.: Fort Collins, CO, USA, 1998.

20. Trung, T.; Tabuc, C.; Bailly, S.; Querin, A.; Guerre, P.; Bailly, J. Fungal mycoflora and contamination of maize from Vietnam with aflatoxin B1 and fumonisin B1. World Mycotoxin J. 2008, 1, 87-94.

21. Silva, C.M.G.; Vargas, E.A. A survey of zearalenone in corn using Romer Mycosep ${ }^{\mathrm{TM}} 224$ column and high performance liquid chromatography. Food Add. Contam. 2001, 18, 39-45.

(C) 2015 by the authors; licensee MDPI, Basel, Switzerland. This article is an open access article distributed under the terms and conditions of the Creative Commons Attribution license (http://creativecommons.org/licenses/by/4.0/). 